\title{
Daring Death among the Tumbuka: A Socio-Semantic Analysis of Death-Related Personal Names
}

\author{
CholaMusonda, SandeNgalande, John Simwinga* \\ University of Zambia
}

*Corresponding Author: John Simwinga, University of Zambia

\begin{abstract}
This study was an attemptto establish the meanings of Tumbuka death daring personal names within the Tumbuka social and cultural setting.It sought to identify and analyse meanings of selected names and to find out the socio-cultural implications of the names and naming patterns and/or strategies that are used among the people in the study area. The qualitative approach was used and the researcher used semistructured interviews, focus group discussions, observation of and interaction with the study population as well as introspection to collect primary data. On a large scale, purposive sampling was the employed technique, and was supplemented bysimple random sampling. Secondary data was obtained from existing Tumbuka literature including school and village registers. Findings showed that, among the Tumbuka people, the first name is bestowed on a child after detachment of its umbilical cord, with the father and grandfather of the child's father being the sole name-givers. First name bestowal arises from different factors, but the study focused only on those names that are influenced by death, with particular reference to those that are used to taunt death. Using the Unified Theory of Names, generated data was analysed. In relation to the findings, it was deduced that personal names in Tumbuka-prone speech communities go beyond being mere personal labels, to expressions and stories that mark the various social and psychological milestones and circumstances surrounding the birth of a child to be named. This in turn makes personal names an integral meaningful part of the Tumbuka cultural heritage which should be explored by scholars.
\end{abstract}

Keywords: Tumbuka, daring, death, names, analysis, socio-semantic, onomastics

\section{INTRODUCTION}

In the field of Linguistics, onomastics is the study of proper names, especially the names of people, also referred to as Anthroponyms and places (Toponyms). A person who studies the origins, distributions and variations of proper names is called an Onomastician. Scholars such as Carol Hough have argued that Onomastics is both an old and young discipline. Old in the sense that since ancient Greece, names have been regarded as central to the study of language, throwing light on how humans communicate with each other and organise the world. The investigation of name origins on the other hand, is more recent, not developing until the twentieth century in some areas, and is still in its formative stages in certain parts of the world. (Hough and Izdebska 2016).

According to Bizhkenovaet. al (2014:81), "Proper names are an important category of words in any language. The origin and the history of proper names (nominapropria) is studied in different fields, but the linguists are interested in proper names the most." This is presumably because they consider this category of words an inalienable part of the language and speech. In spite of this assertion, scholars have argued that the process of giving names to a person is deeply social because of the customs and traditions particularly knitted towards the naming process. It is no wonder research into several generations would largely show that the whole history and development of a society are reflected in the proper names. For instance, people might react to changes in their life by deliberately selecting children's names with meanings that reflect those changes. Hence, making personal names have a living etymon and motivation, which holds true for many African societies.

Among many African cultures, a personal name carries information about the individual that it signifies, the language from which it is drawn and the society that ascribes it. A name may indicate the linguistic structures and phonological processes found in a language, the position of the name bearer in society, and the collective history and life experiences of the people surrounding the individual (Mphade, 2006). 


\subsection{Names and Naming Patterns in African Societies}

Africa has a rich array of naming systems that vary from one society to another. This could be explained by observations madeStewart (1997) and Parham (2002) cited in Liseli (2012:25) who postulate that "The African continent is a vast landmass comprising diverse peoples, ethnic groups, cultures, some 2000 languages, splendid landscapes, and 54 countries." Undeniably, while Africans are by no means a monolithic people, given their varied components (ibid: 25) "when it comes to indigenous naming practices, there are common threads that can be traced throughout this rich tapestry of peoples and their cultures." There is a spirituality that binds African people together, and guides their physical existence. In the African cultural worldview, the essential ingredient and essence of everything, including humans, is spirit. This therefore implies that for Africans, your name is your soul - it has celestial powers and embodies spirit. It is known from the ancient times that names carry some magical power and can influence character and model the fortune of a person.

In another study of anthroponyms in South Africa, Kahari (1990) observed that the choice of a personal name among the Xhosa, Sotho, Tswana and Pondo people of South Africa is influenced by several factors. Among them are religious, commemorative (names marking an event, date or person), derogatory protective names (used as distracters) to make the ancestors think the child is unwanted, owing to previous deaths or misfortune in the family and names which encode social commentary.

In a study carried out in Zambia among the Ng'umbo people, Kabaso (2016:5) submits that "there are situations when a name is bestowed on a child and the child cries persistently." For the Ng'umbo people, this is regarded as rejection of that name by the ancestors. This prompts the elders to rename the child by trial and error, continuously changing the names for reincarnation of the fallen parents until the baby stops crying. This is one of the ritual ceremonies conducted when naming the child. In some circumstances, names are bestowed following the context in which the bearer of the name was born and season of the year (Mutunda, 2008).

\subsubsection{Ethnolinguistic Background of the Tumbuka People}

Literature on the history of the Tumbuka is relatively limited, and this has been acknowledged by scholars such as Chondoka and Botacited in Mushibwe (2009:15) who have claimed that their book is the first to give a correct historical account of the Tumbuka speaking people and have argued that it contains valid historical information.

The Tumbuka people are a distinct ethnic group found in Malawi, parts of Tanzania and Zambia. In Zambia, they are one of the six major tribal groupings found in the Eastern Province. According to Guthries's classification of languages, Tumbuka has been classified as (N21). While Tumbuka as a language is locally referred to as chiTumbuka, which loosely translates to 'language of the Tumbuka people,' the people are known as baTumbuka, that is, 'Tumbuka people.' "This group has a rich array of cultural beliefs, customs and practices with slight variations from other groups in the province" Mushibwe (2009: 14).

The Tumbuka are part of the many and earliest waves of the Bantu immigrants from the Pro-Bantu center in Kola region of the DRC. Like many other tribes in Zambia such as the Bemba, Chewa, and the Nsenga, they left the Luba Kingdom in the early 1400s and settled in Malawi. However, due to population growth, there was need for more land for purposes of agriculture and settlement which prompted one group to settled in present day Lundazi and Chama Districts of the Eastern province of Zambia (Chondoka and Bota, 2007). According to Chondoka and Bota (2007), the Tumbuka coexisted with the Saan who slowly left the area, settling in Namib and Kalahari Deserts of present-day Namibia and Botswana respectively. This study however focuses on the group that settled in Lundazi District of Zambia.

When the Tumbuka people were conquered by the Ngoni people, their chiefs reduced to positions of headmen forcibly usurping their authority and bringing other changes in their lifestyle (Ogot, 1999). Other changes included taking up the Ngoni patrilineal system. The centralised form of chieftainship as well as the system of descent and the payment of the bride wealth.

Economically, the Tumbuka people largely depend on agriculture with the major economic crops, being maize, tobacco and cotton. Cattle rearing is another important aspect of the Tumbuka socioeconomic activities. 


\subsubsection{Tumbuka Naming System}

Among the Tumbuka people, the first name is bestowed on a child after the detachment of its umbilical cord. Traditionally, the father and grandfather of the child's father are the sole name-givers. However, there are circumstances when the paternal uncles and aunts, father of the child to be named or another paternal elderly relative to the father of the newborn might be requested to name a child. Examples of such circumstances include

a. When the rightful name givers are not alive to fulfill their naming duty.

b. When they have not been around for such a long time that they may not be aware of the main events that could help them with the selection of a name that might be a true reflection of the period when and circumstances under which the child to be named was born.

c. There are also instances when there are concurrent infant deaths. When the family and community members realise that it is the same person that had been naming all the children that died, such a person is stopped from naming anymore children because it is believed to be a bad sign which entails changing the name giver. People treat such with suspicion, assuming that the name giver could be involved in witchcraft or could have committed a crime that the ancestors have still not forgiven him for, therefore punishing him by killing all the children he is naming.

Traditionally, males are assigned the responsibility of naming children because the Tumbuka people are a patrilineal group, and traditionally children are believed to exclusively belong to the father's lineage.

\section{Statement of the Problem}

Research on personal names, especially in non-Western societies has attracted scholarly attention in the recent past. However, despite this move, there is scanty literature on personal names in Zambia. Examples of a few comprehensive studies that have been conducted in Zambia include MukumbutaLisimba'sLozi names in Language and Culture (2000); Mwizenge's (2006) work entitled Meaning of Chewa, Nsenga, Ngoni and Tonga names; Luvale Personal Names and Naming Practices: a Sociocultural Analysis by Mutunda (2011) aMorpho-Semantic Analysis of Tonga Given and Nicknames by Hang'ombe (2015); and A morphological and semantic analysis of nicknames in $\mathrm{Ng}$ 'umbo authored by Kabaso (2016).

From these and other studies that have been conducted, it has been established that anthroponyms, especially in African contexts have denotative and connotative meanings which serve various functions in society and have social significance attached to them depending on the society under consideration. As a result, the naming system and/ or name selection for an individual is done with caution. However, among the Tumbuka speaking people of Zambia, little scholarly attention has been given to the naming system, meanings behind personal names and the sociocultural functions that they might serve. The problem under investigation is that we do not know the meanings of death daring personal names in the context of Tumbuka culture.

\section{RESEARCH QUESTIONS}

The study attempted to answer the following questions:

- What are the names to be compiled?

- What is the denotative meaning behind each name?

- What connotations does each name have?

- What are the sociocultural implications of the names and naming patterns and/or strategies used?

\section{LITERATURE REVIEW}

Over the past few decades, studies devoted to exploring different categories and aspects of names have been conducted from diverse perspectives and in different languages. To the best knowledge of the researcher, no study has been conducted in Zambia or anywhere else to investigate the sociosemantic contents of Tumbuka death daring personal names. However, some studies covering many other aspects of names have been conducted outside and within Zambia, and these have been reviewed for the purpose of this study. These names have been categorised into three thematic strands. 


\subsection{Studies on Names as Part of Language Systems}

Names exist as part of the sociolinguistic setting. They are part of every society that gives them and act as a window through which the world is understood and appreciated (Mutunda 2014). Through names, members of a community can express their experiences, feelings, joys or even sorrows.

Mapara et al (2009: 9) notes that names function as conduits of information, especially on society's attitudes or observations towards the named. This therefore indicates that for one to appreciate these names, there is need to have good knowledge of the imagery and metaphor of the language under consideration.

From the foregoing, it can be noted that language emanates from society and the same society uses language to communicate through words and symbols which enable people to evaluate and appreciate the world that they live in. One of the ways in which people use language to this appreciation is through the names that they adopt (Nyota and Mapara 2010). As an aspect of language, names can be used to fuel or minimise conflict because they become conduits through which people communicate their emotions and perceptions.

Among the Tonga people of Zambia, Hang'ombe (2015) discovered that some of the Tonga anthroponyms are drawn from proverbs. Proverbs are important parts of African culture and language, and it is such instances that make it difficult for scholars to detach names in general and personal names in particular from language systems.

\subsubsection{Meaning of Names}

According to Olawale (2005:9), "in Africa, there is so much meaning in a name. If you are given the right name, you start off with certain indefinable but very real advantages." This can be linked to why scholars such as Mbiti (1975:213) see naming in Africa as a big social event because personal names accomplish numerous roles through the names that they carry.

Giving names among the Bantu cultures reflects the sociocultural circumstances of the group and/ or clan. Moyo (1996) observes that the Ngoni-Tumbuka speaking people of northern Malawi prefer names with historical importance like Mapopa (i.e. Wilderness, named after the death of several children) and Tafwachi (What is wrong with us). These names comment on the societal or family condition.

Having carried out a study on the meaning of names among the Zulu society, Koopman (1990) concluded that name givers and bearers of names are aware of the meaning of the name, and the literal meaning of the name is always directly related to the reason for giving it. The ability to read between the lines, as it were, depends upon a cultural continuity in which language is embedded, and which is not open to all. This is where pragmatics comes into play complimented by semantics by looking at the use of context to make inferences about meaning.

For Epstein and Kole (1998:26), "every utterance occurs in a culturally determined context of situation." Therefore, the meaning of a name can only be understood by understanding the context in which naming occurs. This is imperative as the meanings of names are as a result of "complex social negotiations, learned and interpreted through socialisation." which means that "only those who grow up within the community can, perhaps, participate fully in this expanded communicative interaction" (Beattie 1957:37). That is, African names are not always transparent and fully accessible because one needs to understand the language and social context from which the names under consideration are framed.

Despite what has been brought forward, it is important to acknowledge that that there are names whose meanings are difficulty to arrive at. In line with this, Finnegan (1976: 173) suggests that "the colourful often figurative quality of many of these names should be brought out. There are, of course, many names which are relatively straightforward with little overt meaning. Others, however, are richly allusive." This is what makes it necessary that for one to successfully decipher the meaning of names of a particular language, one should have adequate knowledge of that language's imagery and metaphor.

\subsubsection{Studies on names in Zambia}

In Zambia, one of the most comprehensive studies that have been carried out is the work by MukumbutaLisimba (2000) in his Lozi Names in Language and Culture, who asserts that Lozi names 
have meanings and mainly fall into two clear categories. The first category involves names that arise from the circumstances of birth, while the second one consists of names that arise from the sociopsychological environment, and these come from noun and verbal constructions. Despite this clear-cut distinction, it is difficult to categoriseLozi names definitively but can be grouped broadly according to their themes because most of them are concerned with the transience of life, its sufferings and the circumstances at the time of a child's birth.

Mutunda (2011), carried out a study in the North-western province of Zambia where he attempted to provide an interpretive analysis of traditional Lunda personal names. In his research, Mutunda indicated that among the Lunda people, personal names are the foundation of one's identity. Their meanings and circumstances in which they are chosen suggest that they are not mere linguistic phenomenon or arbitrary labels without any meaning. Rather they convey the social and cultural existence of the Lunda people. In his findings, he established that names are rarely given to children randomly but rather are carefully chosen by parents and relatives so as to reflect and reveal the social circumstances in which the baby is born.

Mutunda (2011) further argues that a name is like a document where one can read the history, culture and heritage of the individual or the family in time and space. This is a similar view to other views discussed in the paper from scholars that have pointed out that, personal names provide an important component of African cultural identities. He further argues that, besides having a psychological role in establishing a person's identity, names convey to those who know their origin and meaning, the social and cultural experiences of the people who created them. Above all, names depict how members of a community regard themselves because they reflect values, traditions and events in people's lives. This view is echoed by Mashiri et. al (2013) who assert that naming in African societies often reflects sociocultural and ideological realities of these societies. This therefore shows how sociocultural factors play a major role in the selection and bestowal of personal names.

In addition to the study of Lunda names, Mutunda in his (2016) work, delved into a sociocultural analysis of names and naming systems among the Luvale people, another group found in NorthWestern province, Zambia. Here, it was established that the selection and interpretation attached to the names vary from society to society and from one culture to another. The distinction between African and European personal naming practices is mainly based on the motivation for naming. In light of this, Mutunda (2016) then explored aspects deemed relevant to the Luvale speaking people in regards to the meaning of names, their naming practices and factors that govern the selection of names. In addition to this, he also looked at how the given names are connected to the Luvale culture.

In his findings, Mutunda discovered that among the Luvale, immediately following the child's birth, the midwife also known as Chifungiji, bestows a temporary name or birth name upon a newly born child. However, once the baby's umbilical cord drops off, parents, usually the father, bestows names upon new-born children; but the mother is allowed to name the second child, grandparents and uncles may also name subsequent children. Once a child is given a name by its parents, it will continue permanently and is used in interaction. If it happens that the child cries continuously and inhabitually, this is an indication that the name is inadequate to satisfy some demand of its existence. The spirits indicate through this crying that the name must be changed and another selected. This stems from Luvale's belief in reincarnation. In addition to this, Mutunda (2016) also explored the different types of names, and among them were, names given to children after kinsmen; names based on the manner, time, place and position of a child's birth; names expressing gratitude; those given with the aid of induced pregnancy and proverbial names.

Both Mutunda's studies and Mukumbuta'sare extensive works on Onomastics, and the fact that they were carried out in the geographical location (i.e. Zambia), where the present study was undertaken makes it cardinal because they provided points of reflection on convergent and divergent ideologies pertaining to Zambian Anthrhoponomastics. However, the three studies inclined more towards a sociocultural perspective as opposed to a linguistic one (that offers both denotative and connotative meanings). Even after taking on the sociocultural dimension, they scholars did not give meticulous explanations of the social effects that some names might have on the name bearer and the society in which the bearer is found.

Another study that has looked at personal names in Zambia is that by Chishiba (2017), titled "The Naming Process Among the Lamba People of Zambia: A Sociocultural Study." Using a qualitative 
approach, Chishiba set out to find out whether Lamba names carry any meaning and how these given names are arrived at. In his findings, it was revealed that naming of a child among the Lamba people of the Copperbelt Province in Zambia takes place as soon as the child is born and after the navel has been cut and the new born baby washed in warm water by a midwife. An elderly person from the family is chosen to name the newly born. The name given to the new born baby is usually taken from one of the deceased relatives and it is commonly referred to as the spirit name, implying that the spirit of the dead relative has been reincarnated. It should however be noted that a name given to the child at birth may be changed at a later stage in life. It may be changed during early adolescence or adulthood. However, the changing of names is more common among boys and not girls. Clement Doke (1931) explains that when a child has reached the age bracket of 10 to 12 years, he has a possibility to choose or be given a new name to replace the spirit name which was given to him at birth. The new name can either be chosen by the child himself or it can be given by an elder member of the family such as the grandmother or maternal uncle. The new name has great significance and is closely linked to the character or personality of the child.

According to Hang'ombe's (2015) work, The Morphology and Semantics of Tonga Anthroponyms: the case of given namesand nicknames, morphologically, Tonga given names and nicknames can be divided into deverbals, denominals, deadjectivals and denominals plus deverbals in addition to the common morphological structure of a common noun and proper nouns. Semantically, the study presented the meaning of names based on themes; these included order of birth, character, clan, appreciation, request, travel, work, fertility, social conflict, health, disaster, gestation period, social caution, occupation, hope, social critic, place, joy, love, event, time, death, names explicitly mentioning God and names adopted from the Bible. The results showed that a vast majority of Tonga given names and nicknames are devised from the already existing stock of Tonga vocabulary. Most of the given names are unisex while most of the nicknames are masculine because most of the speech acts are directed towards men.

Kabaso (2016) looked at $A$ morphological and semantic analysis of nicknames in $N g$ 'umbo. The results suggest that the meanings expressed in the selected nicknames in $\mathrm{Ng}$ 'umbo have great social and cultural significance. They convey message to the society about the namer, nicknamed and the society that has created it. The nicknames just like personal names are documents where one can read the history of the individuals in time and space. They are marked by subjectivity, effectivity and critical sense, sense of humour or ridicule. Some conceal as well as create new identities. Through the meanings of these nicknames people are taught about the culture and values of the $\mathrm{Ng}$ 'umbo people.

Another study that has looked at names is Nkolola's (2013) work, which discusses the sources of names, their meanings and naming systems for cattle among the Tonga people of Zambia. Although this is an animal onomasticon (Zoonymy) study, "it looks at the role of cattle names in reconstructing Tonga culture, shedding light on the Tonga people's social world view, socio- economic milieu and the value they attach to cattle" (Lisa, 2013: 81-82). It also reveals that the more times certain types of names appear, the greater the value they express. In her findings Nkolola (2013) states that cattle are not simply viewed as collective possessions. It is no wonder the special individual identity that each cow receives. And just like personal names, cattle names among the Tonga people are not given haphazardly; they relate to the immediate natural environment and social setup and reflect the beliefs and customs of the Tonga people. She writes that some cattle names are inherited from other cattle, some derive from circumstances such as birth or upbringing and others have origins enshrined in an event. Borrowing from Lisa (2013: 108), "Cattle, in this study, are synonymous to human beings in value".

\subsubsection{Other studies on names}

Chauke (1992) who carried out a study among the Bapedi of South Africa, mentions that names play a significant role in reminding the next generation that once upon a time there lived a certain group of people in a particular place. Names serve as symbols which will remain with people throughout their lives. Even the next generation will not be in the dark as far as its culture is concerned because names are a treasure of society and should be carefully preserved since they are intrinsically linked to a people's culture. The Bapedi, like other Africans, give names often guided by the circumstances prevailing at the time of the child's birth, the behaviour of the expecting mother during pregnancy, the history of the familyand religious beliefs. 
Edward (1996), in his work titled "Treasury of Names," remarks that names are a part of every culture and are of enormous importance both to the people who receive and to the societies that give them. Despite their universality, there is a great deal of difference from one culture to another in how names are given. Generally, in cultures with a keen sense of ancestry, children get their names from the totems and family trees of their parents. He also mentions that in some cultures, names are taken from events which happen during the pregnancy of the mother or shortly after the birth of the child, and in others, names are divined through magic and incantation. In some cases, the name given at birth is only the first of several names a person will bear throughout life. When this happens, the new names are given either to mark important milestones in life or to ward off evil spirits by tricking them into thinking that the person with the old name has disappeared. Regardless of when. Why or how often it happens, the giving and receiving of a name is an event of major importance and the significance of names is usually emphasized by elaborate rituals that almost always have deep religious connotations.

Among the Kabre of Togo in West Africa, Batoma (2009), carried out a study, Onomastics and Indirect Communication among the Kabre of Northern Togo, in which he explored the communicative use of proper names among the Kabre. After a brief comparative summary of cultural and methodological approaches to the concept of proper name, Batoma (2009) identified three main categories of Kabre names: the ontological names whose purpose is to capture and express the ontological identity of the name bearers, the pedagogical names which express the plurality of their socio-cultural identities, and the allusive names which are used to convey messages in an indirect way. The emphasis of this article is placed on the last category of names because of the communicative strategies they entail. With focus on allusive names, he illustrates his analysis with examples from two subcategories of Kabre allusive names: the erotic names whose function is educational, and the polemical names which are vengeance-oriented. This provides valid evidence that the Kabre, like many other ethnic groups in Africa, have developed a verbal strategy that involves the use of personal names and animal names to indirectly communicate their feelings and opinions, particularly in conflict-laden situations.

Another scholar, Saarelma-Maunumaa (1999) reveals that the personal naming system of the Ovambos, in Namibia, is based on the idea of name sharing. The study indicates that when a child is born, he or she is first given a temporary name, a birth name that usually indicates the time of the day the baby was born. A few weeks later, a child is then given a real, permanent name, which is used together with a patronymic name. This name is always chosen by the father.

Schottman's (2000) discusses the traditional naming systems among the Baatonu people of northern Benin. For the Baatonu, a person acquires multiple names as he progresses in life and at each stage in life, some of the names are shed off. The multiple names range from a set of ascribed, non-prestigious "little names", through various character-shaping nicknames, to a prestigious, spiritually powerful name. For example, the circumstances of a child's birth define his or her starting point in life, and they will be inscribed to the child's file by means of a set of rule-governed birth names perceived as perfectly suitable for this initial stage of life. However, all Baatonu people aspire to eventually replacing this original set of 'orthodox' name by another name, such as an inherited title name corresponding to an achieved social and spiritual status. It should be noted that Baatonu personal names do not have etymological or referential meanings for the people who use them buthave social and sometimes spiritual meaning.

Kofi (2006) in his paper addresses personal names among the Akan of Ghana. From the data collected and subjected to a sociolinguistic analysis, it was discovered that naming is regarded an important aspect of the Akan society, hence importance is attached to names and naming practices. In addition, names are not considered as arbitrary labels but sociocultural tags that have sociocultural functions and meanings. He further attests that African names are commonly not predictable. For until the child is born and under what circumstances it is born, the name cannot be determined with accuracy.

\section{Methodology}

\subsection{Research Participants}

A group of 35 participants was purposefully selected, with varying ages ranging from 30 to 80 from the study area to be key informants, and help with verification of data thus far gathered. Among them were the headmen from the villages selected and three men and women from their respective villages. 
This was based on the assumption that, mainly, older generations have the required body of knowledge and are vessels of the necessary cultural related issues. They understand and can articulate better most of the things related to culture. In addition to these people were other 25 participants, five chosen from each village through simple random sampling and snowballing. This helped with the speedy collection of data as well as enabled people that had vast knowledge on the subject of names but were not from the older generation and/ or among those selected to also take part in the study.

\subsection{Data Generation}

The study was conducted using the qualitative approach and had employed a descriptive research design. Six main research techniques were used for data collection. These were: simple face to face interviews, focus group discussions, interaction with and observation of the study population, introspection and document analysis. All the recordings which were done during the semi-structured interviews were noted down in a notebook for easy identification on the recorder and then transferred to a computer. Details such as name of the village, the date and time of the recording were noted down for easy identification. In certain instances, data was collected through focus group discussions, and these discussions helped the researcher establish the authenticity of the data thus far gathered, especially from the interviews conducted using simple random sampling, a method that helped with the generation of data. They also helped with the interpretation of certain sections of data generated from secondary sources. The above procedures were supplemented by introspection, based on Tumbuka being the researcher's third language. In addition to this, the researcher also made observations during interactions with the study population, for instance when at the communal water bow holes and maize grinding mill.

\subsection{Data Analysis}

All the files that were recorded using the audio recorder and phone were transferred to a computer. Using Audio Notes 3D, a computer assisted application of qualitative data analysis software (CAQDAS), the researcher listened to the recorded files. This software is an important tool for transcription of audio files because of its enhanced features. These include voice enhancement which can be done through noise removal and audio trimming that allows making text and or photo notes and comments that are synchronised to the audio with time stamps. In addition to this, the software can also remove various static ambient sounds and allow the listener to select the pace at which they would want to listen to the audio file. This made the analysis of data quite easy. During the process, all the names, their meanings and other important data related to the study were noted down with the help of Audio Notes 3D. A socio-semantic analysis of names that were selected for the study were then given in light of the Unified Theory of Names.

\section{RESULTS AND DISCUSSION}

This section presents meaning of Tumbukadeath-daring anthroponyms as gathered during the data collection period. For each name considered in this study, the meaning has been presented and analysed at two levels, with the first level being the denotative meaning, and the second at the level of connotation. The reason for this combination is to help decipher not only what the names mean literally, but what else could be implied or communicated through the meanings that these names bear. The selection has partly been influenced by the different studies that have been reviewed in this paper and have proposed that in African contexts, names usually have a deeper meaning beyond what they might entail on the surface.

Based on the findings of this study, Tumbuka names have both denotative and connotative meanings. This in turn means that for one to fully comprehend and appreciate the meaning of these names, one has to take into consideration the meaning at both levels. It should however be noted that while denotative meanings are generally obvious, it is not always the case with connotative meanings.

\section{Yizenge}

The name means 'let it come.' The name is given to a child born in a family that has suffered frequent deaths of children. Perhaps as many as five consecutive deaths might have occurred. The name Yizenge is therefore given to a child born under such circumstances as a way of challenging the supposed killers to kill again. This is an indirect way of sending a message that the family is not afraid of experiencing the death of a child, thus it could come. 


\section{Chifwenge}

This name means 'let it die.' It should however be noted that the name does not imply that the family wishes for the child to die. On the contrary, they are shaming death for having failed to kill the child so named. The pain of losing a child or any close relation could sometimes affect people's perception of life.

\section{Lyaniso}

The name Lyaniso means 'eat again'. This name is given to a child if in the family, there have been concurrent suspicious deaths of children. The Tumbuka people are quite a superstitious group and sometimes death is believed to be caused by the witches. Therefore, when a child is born under these circumstances, it is named Lyaniso, with the view that the death of the children that a family has lost due to death is not as a result of genuine causes; there is foul play suspected. That is, they are being eaten by the witches and/or wizards. Subsequently, the name is meant to dare the suspected witches to eat [i.e. kill] even the named child like they have done with the rest.

\section{Chakufwa}

The name translates to 'it is dead.' It is given to a child that is born to parents that have experienced concurrent deaths of their children. After having a child that has supposedly outlived the dead siblings, a child is named Chakufwa as a way of mocking death that the named child is already dead and that it is too late for death to catch up with him.

\section{Machilu}

The name Machilu loosely translates to 'manner of jumping (especially if there is a barrier).' The name is given to a child born to the mother that has experienced concurrent miscarriages, still births or children that do not live long enough to grow. Once such a woman finally manages to give birth to a live child or a child that has seemingly outlived the other children, s/he is named Machilu. This name has both connotations of showing surprise at how a child born amidst such terrible things as death could make it as well as showing triumph over death for having missed killing the child.

\section{Malalo}

The name means 'graveyard.' This is a name given to a child that is the first to survive after concurrent deaths of older siblings. The name is symbolic of the resting place for the siblings gone before the named child because the family fears that they might lose even this one to death. Out of pain, the family would name a child graveyard to mock death over how it failed to take this child despite having managed with the other children.

\section{Yafika}

The name literally means 'it has arrived,' with the pronoun it referring to death in this context.The name is given to a child born in a family that has suffered frequent deaths of children. The name Yafikais therefore given to a child born under such circumstances as a way of challenging death to kill again since in the past the arrival of the baby has also heralded the arrival of death.

\section{Chakumanda}

The name can be translated to mean 'it belongs to the grave.' Like other names that have been discussed in the paper, Chakumanda is also given to a baby born into a family that has experienced many deaths of children. This name is aimed at taunting death that the family has had to deal with many deaths already, so what is death waiting for before taking this one as well because the family is alive to the fact that this child too belongs to the grave. It is only a matter of time before returning to its place, the grave.

\section{Kanyifwa}

The name Kanyifwa means 'small or little death.' It is derived from the root -nyifw- which means death and has been used with the prefix ka- which is used to form diminutive forms. The name is given to a child born after concurrent deaths of the siblings born before it. The bestowal of this name implies that just like other children have died, the child so named will also die at a young age. This makes the child a representation of death because the likelihood of surviving is negligible. And because such a child is a representation of the death that has taken away the siblings, s/he becomes death itself, that is Kanyifwa. This is clear mocking death by referring to a child as death. 


\section{Chapasi}

The name means 'belongs to the soil/earth.' Amidst the hopelessness that comes with losing children, people may decide to name their new born child Chapasi, as a way of daring death to kill even the new born since the family has become accustomed to burying its young ones [because they belong to the soil.

\section{Chidongo}

Chidongo means 'soil.' The name is given to a whose parents perceive the child's life as frail just like soil. It could be a child that is born with a disorder or any ailment that is perceived life threatening. The name is deliberately chosen in order to taunt fate (death in this context), to take the child to soil, to the grave.

\section{Chikomeni}

'Kill it' is the literal translation of the name Chikomeni. This name is usually given to children born to a couple that believes thatthere had been foul play involved in the way that they had been losing children. Subsequently, they would name the child that has seemingly outlived its older siblings Chikomeni to dare the suspected killers of the other children to kill even the child so named.

\section{Chiponde}

The name means 'funeral.' It is given to a child born to a woman whose husband had died while she was pregnant and the husband's brother or any other appointed relative married her through chokolo, a bride inheritance custom among the Tumbuka people. The name is also given to a child born amidst many deaths in the family or village at large. Instead of rejoicing for receiving a child, the family becomes grief-stricken due to fear of the possibility of losing another member. Hence, they resort to daring death to take away the child, who has then become synonymous to a funeral.

\subsection{Conclusion}

From what has been presented, it can be concluded that death in a family has the potential to influence the selection of personal names among the Tumbuka people. Culturally, Tumbuka personal names are not just tags that are out there in the community to help distinguish one person from another. They are fundamental clues to help people look into issues pertaining to where they are coming from, dig into their history and acknowledge the fact that they are coming from some place characterised by certain realities which manifest through both the denotative and connotative meanings that are conveyed through names.

Whereas death names could be thought to be laying a trap for the living according to modern thinking, the analysis shows that they are an act of defiance by society in the face of death. Death as scary as it may be, never to be mentioned anyhow, is defeated by trivialising its power through naming of children. Thus, daily, once a child is called by its name, the power of death diminishes in value and power. For future research, besides Tumbuka death daring names, other categories or types of personal names can also be explored. Instead of focusing on Socio-Semantics, other studies can be done by employing other branches of Linguistics such as Morphology, Syntax and Pragmatics among others.

\section{RECOMMENDATIONS FOR FURTHER RESEARCH}

- Besides Tumbuka death daring names, other categories or types of personal names can also be explored.

- Instead of focusing on Socio-Semantics, other studies can be done by employing other branches of Linguistics such as Morphology, Syntax and Pragmatics among others.

\section{REFERENCES}

[1] Batoma A. (2009). Onomastics and Indirect Communication Among the Kabre of Northern Togo. University of Illinois, USA Nordic Journal of African Studies 18(3): 215-234

[2] Beattie, J. H. M. (1957). Nyoro personal names' in Uganda Journal 21.38-47.

[3] Bizhkenova, A., et. al. (2014).Linguo-Semantic Peculiarities of Kazakh Proper Names.3rd International Conference on Information, Business and Education Technology (ICIBET 2014)

[4] Chishiba (2017) "The Naming Process Among the Lamba People of Zambia: A Sociocultural Study. 
[5] Chishiba, G. (2017). The Naming Process Among the Lamba People of Zambia: A Socio-cultural Study. International Journal of Education, Culture and Society 2017; 2(3): 83-87.

[6] Chondoka, A.Y. \&Bota, F.F. (2015).A History of the Tumbuka from 1400 to 1900. U.K: Xlibris

[7] Finnegan, R. (1970). Oral Literature in Africa. Oxford: Oxford University Press

[8] Hang'ombe, K. (2015). A Morphosemantic Analysis of Tonga Anthroponyms: A Case of Tonga Given Names and Nicknames. Unpublished Masters Dissertation.The University of Zambia.

[9] Hough, C. and Izdebska, D. (eds.) (2016).The Oxford Handbook of Names and Naming. Oxford University Press

[10] Kabaso, F.M. (2016). A Morphological and Semantic Analysis of Nicknames in Ng'umbo. Unpublished Master's Thesis. The University of Zambia.

[11] Koopman, A. (1990). 'Some notes on the Morphology of Zulu Clan Names. South African Journal of African Languages. 4.1: 333-37.

[12] Mapara, J.et. al. (2009). Indigenous Knowledge Systems in Zimbabwe: Juxtaposing Post-colonial Theory. The Journal of Pan African Studies, 3.139-155. 2009.

[13] MashiriPedzisai, E. Chabata and E. Chitando. (2013). A Sociocultural and linguistic analysis of postcolonial Christian naming practices in Zimbabwe. Journal for Studies in Humanities and Social Sciences

[14] Mbiti, J. S. (1975). Introduction to African Religion.London: Heinemann.

[15] Moyo, T. (1996).Personal Names and Naming Practices in Northern Malawi.Nomina Africana. 10.1 and 2 : 10-19.

[16] Mphande, L. (2006). Naming and Linguistic Africanisms in African American Culture.In Selected Proceedings of the 35th Annual Conference on African Linguistics, ed. John Mugane et al., 104-113. Somerville,MA: Cascadilla Proceedings Project

[17] Mukumbuta, L. (2000).Lozi Names in Language and Culture.Libreville: International Centre for Bantu Civilisations

[18] Mushibwe (2009:15)

[19] Mutunda, S. (2011).Personal Names in Lunda Cultural Milieu. U.S.A.: University of Arizona.

[20] Mutunda, S. (2011).Personal Names in Lunda Cultural Milieu. U.S.A.: University of Arizona

[21] Mutunda, S. (2016).Luvale Personal Names and Naming Practices: A Socio-Cultural Analysis. International Journal of Education, Culture and Society 2016; 1(3): 75-81.

[22] Mwizenge, T (1988). What does Your African Name Mean? The meanings of Indegenous Names Among the Tonga of Southern Province. Lusaka: Institute of African Studies-UNZA.

[23] Nkolola-Wakumelo (2013). „Names of Cattle and the Cattle-Naming System Among the Tonga of Zambia In Cliggett L. and Virginia B. (Eds). Tonga Timeline: Appraising Sixty Years of Multidisciplinary Research in Zambia and Zimbabwe (pp 81-108.). Lusaka: Lembani Trust.

[24] Nyota, S. and Mapara, J. (2010).Shona anthroponyms as summaries of the namers and the named's experiences. Unpublished manuscript

[25] Olawale, F. (2005).News Journal Community Advisory Board.Ibadan: Heinemann.

[26] Saarelma-Maunumaa, M. (2003) EdhinaEkogidho - Names As Links: The Encounter between African and European Anthroponymic Systems among the Ambo People in Namibia. Unpublished Dissertation. University of Helsinki.

[27] Stewart, J. (1996). African names: First and last names from the African continent. New York: Carol Publishing Group

\section{AUTHORS' BIOGRAPHY}

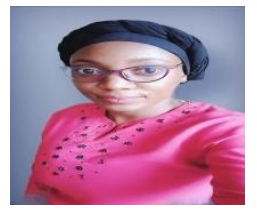

Ms. MusondaChola, Staff Development Fellow, Department of Literature and Languages, University of Zambia, Lusaka, Zambia

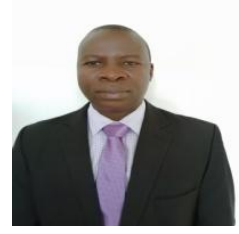

Dr. SandeNgalande, Lecturer, Department of Literature and Languages and Director, Confucius Institute, University of Zambia, Lusaka, Zambia 


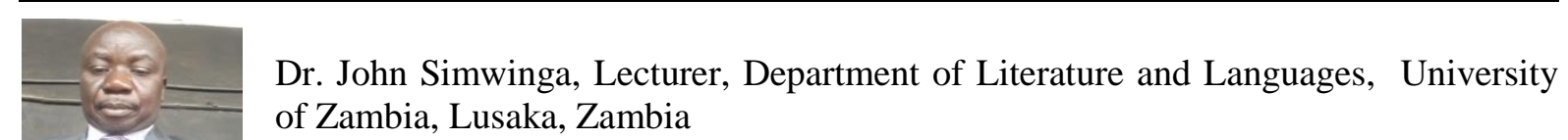
of Zambia, Lusaka, Zambia

Citation: CholaMusonda, SandeNgalande, John Simwinga. "Daring Death among the Tumbuka: A SocioSemantic Analysis of Death-Related Personal Names". International Journal of Humanities Social Sciences and Education (IJHSSE), vol. 6, no.7, 2019, pp. 109-120. doi: http://dx.doi.org/10.20431/2349-0381.0607012.

Copyright: (C) 2019 Authors. This is an open-access article distributed under the terms of the Creative Commons Attribution License, which permits unrestricted use, distribution, and reproduction in any medium, provided the original author and source are credited. 